\section{New Approach to mRNA Quantification: Additive RT-PCR}

BioTechniques 21:202-204 (August 1996)

The quantification of a determined mRNA by reverse transcription polymerase chain reaction (RT-PCR) is based on the linear fitting of the "exponential" growth obtained after different concentrations of the template are amplified. Usually a modified internal standard, which allows the quantification by comparing bands or extrapolating in a standard curve, is used. We propose a method that uses an unmodified internal standard identical to the target molecule, which simplifies and improves the methodology. We also propose a logistic fitting of the standard curve as an alternative to the linear-exponential adjustment.

For this purpose, we have studied scavenger receptor genes and quanti-

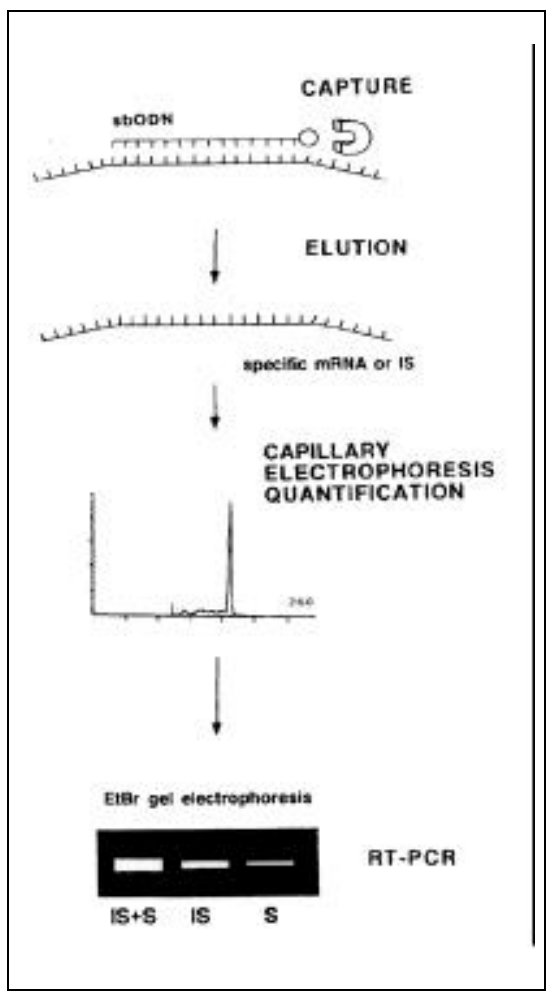

Figure 1. Schematic view of the procedure used to obtain the internal standard and its application to additive RT-PCR. sbODN: selected biotinylated oligonucleotide; IS: internal standard; S: sample of total RNA. fied their expression. These receptors mediate the binding and uptake of chemically modified lipoproteins and are therefore involved in atherosclerosis. To obtain specific scavenger receptor mRNAs to be used as an internal standard, total cytoplasmic RNA from $1.5 \times 10^{8}$ THP- 1 cells derived from macrophages was isolated by the guanidinium isothiocyanate method (2). Fibroblast RNA was used as a negative control. The RNA was hybridized with 150 pmol of a specific biotinylated oligonucleotide complementary to both scavenger receptor mRNAs 5'-CTAATTTACTGATTTCCTCTTGTTGTTTGAAGGTATTCTCTTGGATTTT-3' (4) at $70^{\circ} \mathrm{C}$ for $5 \mathrm{~min}$. Streptavidin MagneSphere ${ }^{\circledR}$ paramagnetic particles (2 mg; Promega, Madison, WI, USA), washed three times with $0.5 \times$ standard saline citrate (SSC), were then added. After $2 \mathrm{~min}$, the beads were captured by using a magnetic rack, and then three stringent washes with $0.5 \times \mathrm{SSC}$ were done. To elute the specific mRNA, $500 \mu \mathrm{L}$ of RNase-free water were added. The sample was concentrated by using $3 \mathrm{M}$ ammonium acetate
(0.1 vol), $20 \mathrm{mg} / \mathrm{mL}$ glycogen (Boehringer Mannheim, Mannheim, Germany) $(0.02 \mathrm{vol})$ and 2-propanol (2 vol $)$ and redissolved in $10 \mu \mathrm{L}$ of RNase-free water, and the concentration was determined by capillary electrophoresis (CE) (5). Then, $1.2 \times 10^{4}$ copies of the specific mRNA were reverse-transcribed in the presence of $0.8 \mu \mathrm{g}$ fibroblast total RNA, with 40 U RNasin ${ }^{\circledR}$ (Promega), $1 \mathrm{mM}$ deoxyribonucleoside triphosphates (dNTPs), $60 \mathrm{U}$ of Moloney murine leukemia virus reverse transcriptase (Promega) and $2.5 \mathrm{mM}$ of random hexamers in $20 \mu \mathrm{L}$ RT buffer (Promega) at $42^{\circ} \mathrm{C}$ for $45 \mathrm{~min}$ and then incubated at $95^{\circ} \mathrm{C}$ for $10 \mathrm{~min}$. cDNA was amplified with the addition of 10 pmol of the upper primer 5'-CCACATTGCTTGATTTGCAGCTC-3', 10 pmol of the lower primer 5'-CTCCCACCGACCAGTCGAACTTTCGTAA$3^{\prime}$ and 2.5 U Taq DNA Polymerase (Promega) in $80 \mu \mathrm{L}$ of $1 \times$ PCR buffer. PCR primers were selected by using the "Oligo" program (MedProbe, Oslo, Norway). The amplification protocol was: $20 \mathrm{~s}$ at $95^{\circ} \mathrm{C}, 15 \mathrm{~s}$ at $60^{\circ} \mathrm{C}$ and $40 \mathrm{~s}$ at $72^{\circ} \mathrm{C}$ for 30 cycles, then $7 \mathrm{~min}$ at

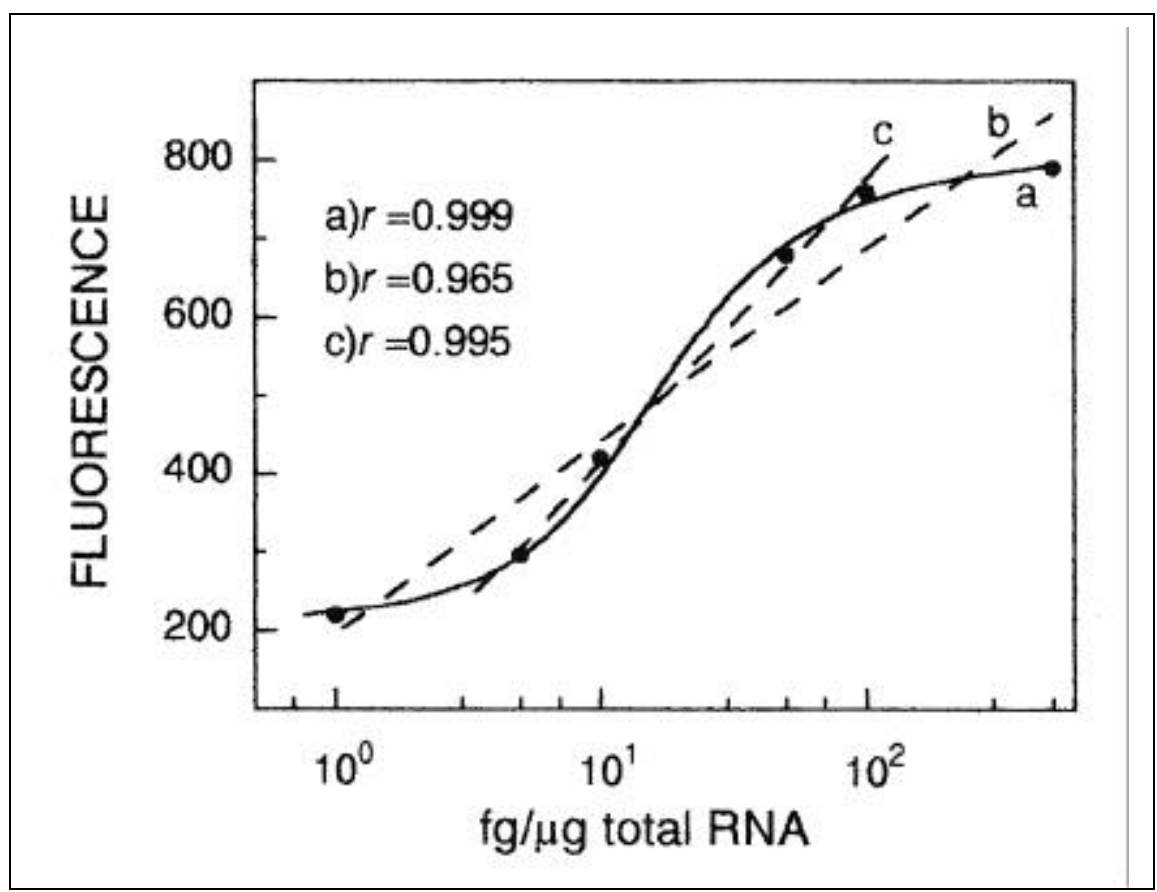

Figure 2. Scavenger receptor type I mRNA standard curve. Intensity of fluorescence (measured by using Hoechst reagent 33258 and a Hitachi F-2000 fluorometer) vs. different amounts of the specific mRNA in cycle 30 . Different adjustments were applied: (a) logistic, defined by equation $y=[(\mathrm{a}-\mathrm{d}) /(1+$ $\left.\left.(\mathrm{x} / \mathrm{c})^{\mathrm{b}}\right)\right]+\mathrm{d}$, in which $\mathrm{a}=800.5, \mathrm{~b}=-1.32, \mathrm{c}=16.2$ and $\mathrm{d}=201.3$, (b) linear-exponential, to a wide range $(1-500)$ and (c) linear zone adjustment to a narrow range (4-100) where each point was assayed in triplicate, with a CV $<9.2 \%(10-\mathrm{fg}$ point $[\mathrm{n}=10] \mathrm{CV}$ of $6.3 \%)$ 
$72^{\circ} \mathrm{C}$ in a DNA Thermal Cycler 480 (Perkin-Elmer, Norwalk, CT, USA). A 513-bp band was obtained as expected and was confirmed by sequencing. To check for possible contamination, we also amplified by RT-PCR the specific mRNA by using primers for IL- $1 \alpha$ and $\beta$-actin genes, and no bands were observed. A standard curve of 5, 10, 50, 100 and $500 \mathrm{fg}$ of the captured specific mRNA was obtained after 30 amplification cycles. Ten femtograms were selected as the internal standard for the additions (see below).

Total RNA from $10 \mathrm{~mL}$ peripheral blood mononuclear cells (PBMC) of different individuals was isolated as previously described. Duplicated tubes containing $0.8 \mu \mathrm{g}$ of total RNA each were set up. Ten femtograms of the internal standard were added to one of them (Figure 1) and then were amplified by RT-PCR. PCR products were electrophoresed on an agarose gel and stained with ethidium bromide. The optical density of the 513-bp band, in a digitalized picture, was measured by using a Sun Spark Station (Visage software; Millipore, Bedford, MA, USA). In addition, $15 \mu \mathrm{L}$ of each RT-PCR product was also quantified by measuring the intensity of fluorescence using Hoechst reagent 33258 (Polysciences, Warrington, PA, USA) as the dye ( $\lambda$ exc: $365 \mathrm{~nm}$ and $\lambda$ em: $460 \mathrm{~nm}$ ) with a Hitachi F-2000 Fluorometer (Hitachi, Tokyo, Japan).

mRNA concentration was calculated by applying two fittings to the standard curve obtained, a linear-exponential and a logistic mathematical adjustment defined by the equation $\mathrm{y}=[(\mathrm{a}-\mathrm{d}) /(1+$ $\left.\left.(\mathrm{x} / \mathrm{c})^{\mathrm{b}}\right)\right]+\mathrm{d}$, in which a = maximal value of the signal, $b=$ slope parameter, $\mathrm{c}=$ value at inflection point, $\mathrm{d}=$ minimal value signal (SigmaPlot ${ }^{\mathrm{TM}}$; Jandel Scientific, San Francisco, CA, USA). It was observed that the PCR process with Taq DNA polymerase is better fitted with a logistic than a linear-exponential adjustment when a wide range of concentrations is studied. Results were extrapolated to a standard curve based on a logistic equation and compared with the linear-exponential curves. These fittings showed similar results, but the logistic one was more accurate when applied to a wider range of concentrations (Figure 2). This be- havior of Taq DNA polymerase has also been shown by other authors who have studied activity vs. increasing cycles and template concentrations (1).

By definition, the best internal standard to quantitate PCR products is a template identical to the target sequence to be studied, since this ensures an identical amplification efficiency. The efficiency and detection signal of PCR products change when an internal standard of a different size or sequence from the wild-type is used (3). Methods used so far employ modified internal standards to differentiate both molecules. This procedure has led to the necessity of producing, in vitro, large amounts of the internal standard that has to be modified; therefore, values have to be corrected by at least two factors in these competitive assays. First, the correction here relates to the efficiency of both RT and PCR itself. Second, the correction of the signal, when an internal standard of a different size is applied, is irrespective of the detection system (fluorescence, radioactivity or optical density). In the method described in this work, the addition of an identical internal standard has two practical features. It increases the measurable signal to a range of the curve with higher sensitivity and controls the accuracy in each single sample. Duplicated aliquots with and without an internal standard can be used to calculate the recovery of the standard in each sample (Table 1). Moreover, this protocol is more simple than the classical competitive PCR because no standards with different concentrations are used for each assay, as well as the unnecessary correction of the efficiency and signal detection. Additive quantitative RT-PCR has also been applied to other mRNAs such as the angiotensin II receptor and human immunodeficiency virus (HIV)-1 RNA (data not shown). Some variations in the method could be related to the internal standard since three different ones can be used, $(i)$ specific mRNA from a gene (real concentration of the sample), (ii) specific cDNA (subjected to variations in retrotranscription efficiency) and (iii) DNA such as a purified PCR product, which depends on RT and PCR efficiency mainly in the first cycles. Although each one could be used to quantify gene expression, we have concluded that a specific mRNA is the optimal choice since it is subjected to less variations during the process and therefore leads to more accurate results.

\section{REFERENCES}

1.Berry, N., K. Ariyoshi, O. Jobe, P.T. Ngum, T. Corrah, A. Wilkins, H. Whittle and R. Tedder. 1994. HIV type 2 proviral load measured by quantitative polymerase chain reaction correlates with $\mathrm{CD}^{+}$lymphopenia in HIV type 2-infected individuals. AIDS Res. Hum. Retroviruses 10:1031-1037.

2.Chomcznsky, P. and N. Sacchi. 1987. Singlestep method of RNA isolation by acid guanidinium thiocyanate-phenol-chloroform extraction. Anal. Biochem. 162:156-159.

3.Gemen, B.V., T. Kievits, R. Shukkink, D.V. Strijp, L.T. Malek, R. Sooknanan, H.G. Huisman and P. Lens. 1993. Quantification of HIV-1 RNA in plasma using NASBA ${ }^{\mathrm{TM}}$ during HIV-1 primary infection. J. Virol. Meth. 43:177-188.

4.Matsumoto, A., M. Naito, H. Itakura, S. Ikemoto, H. Asaoka, I. Hayakawa, H. Kanamori, H. Aburatani, et al. 1990. Human macrophage scavenger receptors: primary structure, expression and localization in atherosclerotic lesions. Proc. Natl. Acad. Sci. USA 87:9133-9137.

5.Reyes-Engel, A. and J.L. Dieguez-Lucena. 1993. Direct quantification of specific mRNA using a selected biotinylated oligonucleotide by free solution capillary electrophoresis. Nucleic Acids Res. 21:759-760.

This work was supported by two personal grants, Grant Nos. 94/5377 and 94/5334, from FIS (Ministerio de Sanidad y Consumo, Spain). Address correspondence to A. Reyes-Engel, Department of Biochemistry and Molecular Biology, Faculty of Medicine, University of Malaga, 29080-Málaga, Spain.

Received 21 April 1995; accepted 25 January 1996.

\section{A. Reyes-Engel, J. García- Villanova, J.L. Dieguez- Lucena, N. Fernández-Arcás and M. Ruiz-Galdón University of Malaga Málaga, Spain}

